\title{
Fabrication and Characterization of Natural Rubber-Based Magnetorheological Elastomers at Large Strain for Base Isolators
}

\author{
Chan Woo Lee $\mathbb{D}^{1},{ }^{1}$ In-Ho Kim $\mathbb{D}^{D},{ }^{2}$ and Hyung-Jo Jung $\mathbb{D}^{2}$ \\ ${ }^{1}$ Department of Civil and Environmental Engineering, Korea Army Academy at Yeong-cheon, \\ Yeong-cheon 38900, Republic of Korea \\ ${ }^{2}$ Department of Civil and Environmental Engineering, Korea Advanced Institute of Science and Technology, \\ Daejeon 34141, Republic of Korea \\ Correspondence should be addressed to Hyung-Jo Jung; hjung@kaist.edu
}

Received 27 November 2017; Accepted 29 April 2018; Published 4 June 2018

Academic Editor: Jörg Wallaschek

Copyright (C) 2018 Chan Woo Lee et al. This is an open access article distributed under the Creative Commons Attribution License, which permits unrestricted use, distribution, and reproduction in any medium, provided the original work is properly cited.

To withstand harsh conditions and have a moderate strength, it is desirable to use natural rubber for base isolators. In addition, previous studies have measured the magnetorheological (MR) effect under low-strain range, mostly within $10 \%$. In the reality, it is necessary to evaluate the performance under large-strain range for base isolators. In this study, material properties of natural rubberbased MREs with various mixing ratios were evaluated under large-strain range ( $100 \%)$. In the first step, MREs with various iron ratios were fabricated and evaluated to observe the MR effect according to the ratio and arrangement of iron powder. As a result, the highest MR effect $(22.0 \%$ at $100 \%$ strain) and damping ratio $(10.29 \%)$ were observed in the sample with $35 \%$ iron ratio, and the MR effect of the isotropic and the anisotropic MRE did not show significant difference under large-strain (50 100\%). In the second step, MRE samples containing the optimum iron ratio (investigated in the first step) and various mixing ratios of carbon black and naphthenic oil were prepared. As a result, the MRE containing 60phr of carbon black and 40phr of naphthenic oil had the highest MR effect (33.8\% at $100 \%$ strain). Compared to the case without additives, it showed an obvious improvement.

\section{Introduction}

A base isolation strategy reduces the acceleration response by moving the natural period of the base isolated structure from the short period to the long period because strong seismic responses appear mainly in the short period [1]. However, conventional base isolators only respond to predicted earthquakes. That means the device is not adaptive when unexpected earthquakes occur [2]. Recent studies have reported that conventional base isolators are particularly vulnerable to near-fault earthquakes [3, 4]. Among near-fault earthquakes, a fault-normal earthquake observed in an area orthogonal to the fault direction causes a higher response in a wider periodic band than a fault-parallel earthquake [5]. Therefore, such seismic waves can exceed the permissible displacement of the base isolator with a long period pulse and high amplitude. In the case of the Mexico City earthquake (1985), the seismic waves occurred in the soft ground around the lake were mainly observed in the 1.5 to 2.5 second region near the design period of the base isolated structure [3]. This may cause a resonance phenomenon, which may be even more dangerous.

To solve this problem, an active or semiactive control strategy that can adapt to various dynamic loads is required. Among them, a smart material called Magnetorheological Elastomer (MRE) has led to an emergence of a new type of base isolation device that overcomes the shortcomings of conventional base isolators by controlling real-time stiffness. The MRE is a material with a magnetorheological (MR) effect that adjusts elastic modulus and damping ratio by applying magnetic field [6-9]. The MR effect was first discovered in 1948 by Jabob Rabinow [10, 11], and since then many systems utilizing MR fluids (MRFs) have been invented. However, MRFs have some problems such as deposition, sealing issues, and environmental contamination [12]. Moreover, MRF is used as a system that operates in one direction, while MRE is used as a system that operates in various directions. The main difference is that MRE can adjust the natural frequency 
by adjusting the stiffness while MRF controls just damping force. Thus, the MRE which is a rubber with ferromagnetic particles has a number of advantages over MRF. For these reasons, MRE is applied not only to base isolators but also to tuned vibration absorbers (TVAs) and sensing devices that use variable stiffness of rubber.

It has been reported that the change of damping ratio of the MRE under the external magnetic field is almost negligible compared to the change of stiffness [13]. Thus, the MR effect is defined as the change in elastic modulus depending on the magnetic field. It can be expressed as

$$
M R \operatorname{effect}(\%)=\frac{G\left(B_{M R E}\right)-G(0)}{G(0)} \times 100
$$

where $G\left(B_{M R E}\right)$ is the shear elastic modulus when a magnetic field is applied to MRE, and $G(0)$ is shear modulus when there is no magnetic field. The control of the elastic modulus enables the adjustment of the natural period of the base isolated structure. The relationship can be expressed as

$$
\frac{G\left(B_{M R E}\right)-G(0)}{G(0)}=\frac{\{T(0)\}^{2}-\left\{T\left(B_{M R E}\right)\right\}^{2}}{\left\{T\left(B_{M R E}\right)\right\}^{2}}
$$

where $T\left(B_{M R E}\right)$ are natural period when the magnetic field is applied to the MRE, and $T(0)$ are the natural period when there is no magnetic field. As major factors of the MR effect, the volume fraction, the shape, and the size of the magnetic particles are influential. According to the finite element analysis by Davis [7], the highest MR effect was obtained when the particle volume fraction was $27 \%$. Kallio et al. [14] observed an increase in stiffness and damping ratio when the isotropic MRE exceeded $15 \%$ of the particle volume fraction. Lokander et al. [8] observed that the MR effect is maximized when the volume fraction of particles is close to Critical Particle Volume Concentration (CPVC), which is defined as the ratio of apparent iron density to real iron density. In addition, among the iron particles, the ASC300 (Hoganas, Sweden) with the size distribution of $60 \mu \mathrm{m}$ or less and irregular shape had the highest MR effect. The type of rubber had no effect on the absolute MR effect. However, as the more flexible rubber was used, the initial stiffness was lowered. Therefore, the relative MR effect can be enhanced by the addition of a plasticizer or oil. Chen et al. [15] observed that the addition of carbon black increased the mechanical properties of MREs and showed higher MR effect. Regarding the arrangement of iron particles, Chen et al. [16] observed higher MR effect in anisotropic MREs than isotropic MREs. Especially, as the magnitude of the applied magnetic field increased (up to 1 Tesla), thicker chain structures were formed and the MR effect was high. In the test for strain dependence, the maximum MR effect appeared in a relatively small strain region because the magnetic force is related to the mutual distance of the magnetic particles [17].

So far, several MRE-based isolation devices have been proposed [18-28]. Most of the proposed MRE-based base isolators utilized silicone rubber that cures at room temperature conditions without any special equipment. However, silicone rubber generates air bubbles on the contact surface, resulting in poor adhesion, which reduces the concentration of the magnetic field [28]. Chen et al. [29] observed that the MRE using natural rubber is superior in mechanical properties to the MRE using silicone rubber. Furthermore, if excessively soft rubber like silicone is used for base isolators, it becomes difficult to withstand harsh conditions under earthquakes. According to the International Organization for Standardization (ISO) 22762 [30], natural rubber is proposed as the material of base isolators. And the proper shear modulus of the natural rubber-based elastomeric isolators for the building is $0.3 \sim 1 \mathrm{Mpa}$ and that for bridge is 0.8 $\sim 1.2 \mathrm{Mpa}$. Wahab et al. [28] fabricated and evaluated a natural rubber-based MRE isolator. The device showed a good MR effect of $120 \%$ under a strain of $10 \%$ and a magnetic density of $0.8 \mathrm{~T}$. However, considering the realistic range of motion of the base isolation device, the strain range of $10 \%$ is insufficient. According to the ISO 22762, the shear elastic modulus of the base isolator is to be measured at $100 \%$ or $175 \%$ strain amplitude. Therefore, it is necessary to evaluate the performance over a wider range of strain amplitude for practical applications.

In this paper, material properties of natural rubber-based MREs with various mixing ratios were evaluated in proper test conditions for base isolators. In the first step, MREs with various iron ratios were fabricated and evaluated to observe the MR effect according to the ratio and arrangement of iron powder. The samples were fabricated in two types of isotropic and anisotropic samples. Their microstructure and magnetic properties of the samples were observed by a scanning electron microscope (SEM) and a vibrating sample magnetometer (VSM), respectively. Then the dynamic properties (initial shear modulus, MR effect) of the MREs at large-strain amplitude (up to 100\%) were evaluated under the absence or presence of a magnetic field using a dynamic testing machine. In the second step, MRE samples containing the optimum iron ratio (investigated in the first step) and various mixing ratios of additives (carbon black, naphthenic oil) were prepared. Their dynamic properties were evaluated under various strain and frequency conditions and the enhancements of the MR effect by additives were compared.

\section{Experimental}

2.1. Fabrication of MRE Samples. Four main materials were used to fabricate the MRE samples. The matrix was natural rubber (SVR CV60, Hung Thinh, Vietnam, specific gravity: 0.92, Mooney viscosity: 60). The iron powder used was ASC300 (specific gravity: 7.5, particle size $<60 \mu \mathrm{m}$ ) from Hoganas Co., Ltd., which exhibited the maximum MR effect among the iron powders investigated by Lokander et al. [8]. As additives, carbon black (FEF-N550, Orion, specific gravity: 1.82) and naphthenic oil (N-2, specific gravity: 0.92$)$ were used.

The fabrication procedures of MRE samples consisted of mixing, extruding, molding, and curing as the ordinary rubber synthesizing process. First, natural rubber, iron powder, and additives were added to a Banbury mixer (HYB3L, Hyupyoung, Korea) and mixed for 15 minutes. Then, the mixture was passed through a roller mill (BS-M08S, 
TABLE 1: MRE samples with various iron volume fractions.

\begin{tabular}{lcc}
\hline Iron volume fraction (\%) & Isotropic & Anisotropic \\
\hline 0 & 0 & - \\
15 & $\bigcirc$ & $\bigcirc$ \\
25 & 0 & $\bigcirc$ \\
30 & 0 & $\bigcirc$ \\
35 & 0 & 0 \\
\hline
\end{tabular}

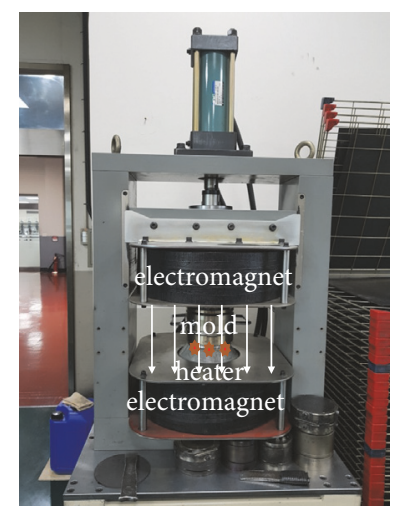

FIgURE 1: Magnetic-thermal curing machine.

Bongshin, Korea). Then the sample corresponding to the mold shape was cured in a magnetic-thermal curing machine (Figure 1). The size of the sample was $25 \mathrm{~mm} \times 25 \mathrm{~mm} \times 5 \mathrm{~mm}$ in the shape of a rectangle (Figure 2) based on the ISO 22762. Curing conditions were $160^{\circ} \mathrm{C}$ and $10 \mathrm{MPa}$. When there was no magnetic field, the sample became an isotropic MRE. On the contrary, when the magnetic field of $1.5 \mathrm{~T}$ was applied, an anisotropic MRE with chain structures was produced. At first, to investigate the MR effect according to the iron ratio and the arrangement, various samples of iron powder volume fractions were synthesized. After investigating the effect of the iron powder, to investigate the effect of carbon black and naphthenic oil on the material properties of MRE, samples with various mixing ratios of the additives were prepared. The prepared MRE samples are summarized in Tables 1-2. Among them, the MRE containing 60 parts per hundred resin (phr) of carbon black and 20phr of naphthenic oil was too tough to be synthesized and excluded from the experiment.

\subsection{Observation of Microstructure and Magnetization Curves.} To observe the microstructure of isotropic and anisotropic samples with different iron ratios, SEM (SU8230, Hitachi, Japan) images were taken at an accelerating voltage of $10 \mathrm{kV}$. The magnetization curves of each sample were also examined using a VSM (MPM3S-Evercool, Quantum Design, USA) to compare the magnetic saturation values according to the iron powder volume fractions.

2.3. Dynamic Shear Test. Two movable neodymium magnets (N35, $10 \mathrm{~cm} \times 10 \mathrm{~cm} \times 10 \mathrm{~cm}$ ) were installed as shown in Figure 3 to apply an adjustable magnetic field during shear tests. The SS41 steel plate having high permeability and the centrally located MRE sample construct a closed loop forming a strong and uniform magnetic field. Numerical analysis results using Finite Element Magnetics (FEMM) [31] showed that the maximum $0.9 \mathrm{~T}$ was achieved when the magnets were closest as shown in Figure 4. The zero position of length in Figure 4 means the top point of the red line (the point corresponding to the highest point of the magnet) in Figure 4. Actual measurements at the surface of the MRE sample using the gauss meter (5180, F. W. Bell, USA) showed the similar result with $0.94 \mathrm{~T}$. As the distance from the MRE to the magnet increased, the magnetic field gradually weakened. This aspect is shown in Figure 5. The test rig was installed in a dynamic material testing machine (Instron 8801, USA) and dynamic shear tests were performed under various external conditions.

\section{Results and Discussion}

3.1. Evaluation of MRE Properties with Various Iron Powder Volume Fraction and Iron Arrangement. MRE samples with different volume fractions $(0,15,25,30$, and $35 \%)$ of iron powder were prepared without adding any other additives to investigate the optimum volume fraction of iron powder, which is most influential to the MR effect. The MREs were fabricated in both isotropic and anisotropic types. As a result of SEM images, the higher the volume fraction of iron particles is, the denser the distribution of particles was observed as shown in Figure 6. In the case of the 15\% anisotropic MRE, the chain structures were formed according to the direction of the magnetic field while isotropic MRE showed uniform distribution. However, in the case of 35\% anisotropic MRE, it was too dense and the chain structures were hardly observed even though the magnetic field was applied.

As shown in Figure 7, the higher the volume fraction of iron particles is, the higher the intensity of the magnetic saturation was reached. It means that the MRE containing a high volume fraction of iron particles is highly influenced by the magnetic field. In addition, the magnetic saturations were achieved at a magnetic field of about 1Tesla in air (10kOe).

In the dynamic shear test, the MR effect was evaluated under the change of the magnetic field at the strain range of 50 and $100 \%$ and excitation frequency of $0.5 \mathrm{~Hz}$. The hysteresis curves were obtained from the 9th to 11th cycles of excitation for each sample. The reason for not considering up to 8 th cycles is to exclude the stress-softening phenomenon known as the Mullins effect. Due to the Mullins effect, the strongest stress is shown in the first cycle, and the stress in subsequent cycles gradually decreases and converges to a value [32]. As shown in Figures 8-9, the results showed that the sample containing higher iron volume fractions showed a higher MR effect. The effective stiffness in the hysteresis curve is calculated in accordance with the ISO 22762 as follows:

$$
K_{h}=\frac{Q_{1}-Q_{2}}{X_{1}-X_{2}}
$$

where $Q_{1}, Q_{2}, X_{1}$, and $X_{2}$ represent the maximum and minimum shear force and maximum and minimum displacement, 
TABLE 2: MRE samples with carbon black and naphthenic oil.

\begin{tabular}{cccc}
\hline Iron volume fraction (\%) & Carbon black $\left(\mathrm{phr}^{\mathrm{a}}\right)$ & Naphthenic oil (phr) & Isotropic \\
\hline & 20 & 20 & 0 \\
35 & 40 & 20 & Synthetic failure (too tough) \\
& 60 & 20 & 0 \\
& 20 & 40 & 0 \\
& 40 & 40 & 0 \\
\hline
\end{tabular}

a phr: parts per hundred resin (mass proportion to rubber).

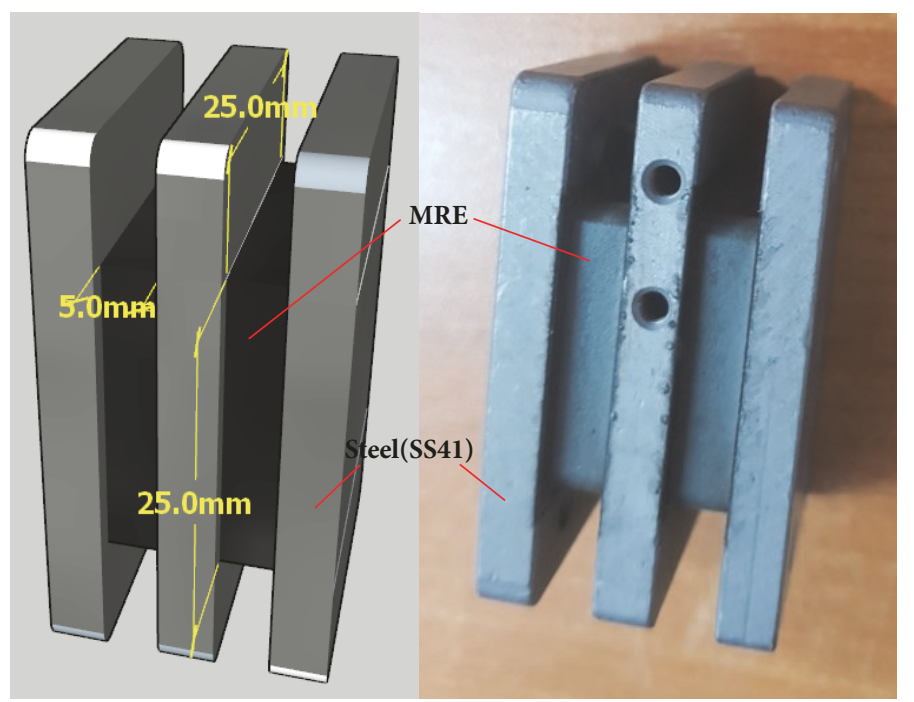

FIGURE 2: MRE sample.

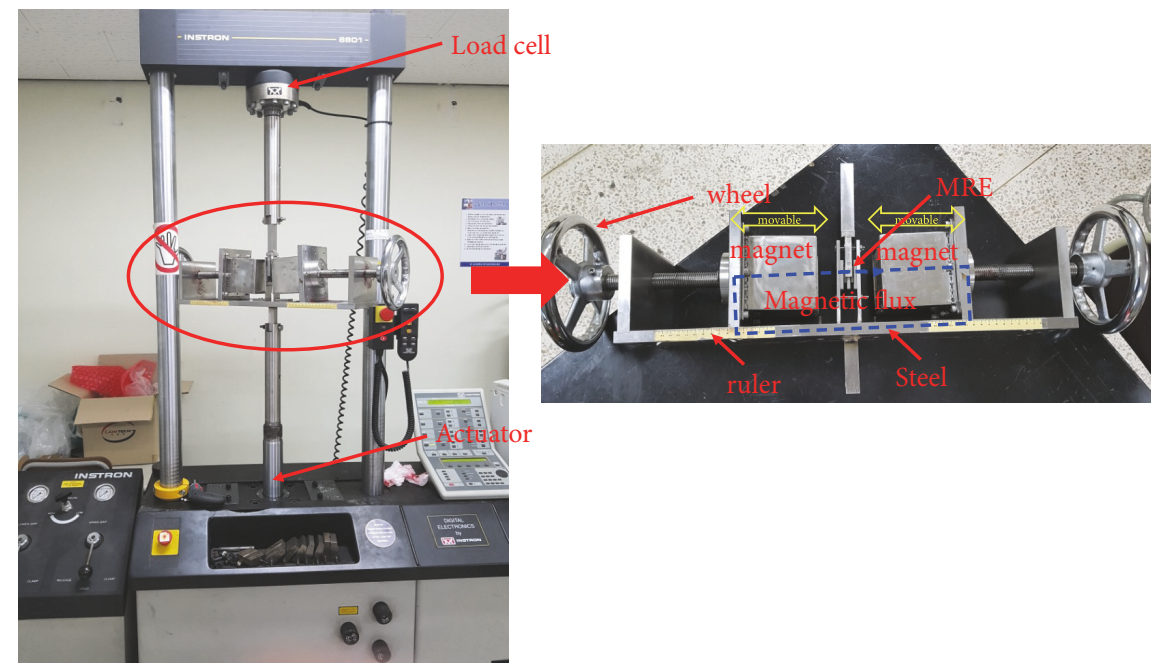

Figure 3: Dynamic shear test setup.

respectively. The horizontal stiffness of the MRE is expressed as

$$
K_{h}=\frac{G A}{H}
$$

where $G, A$, and $H$ are the shear modulus, the cross-sectional area, and the height of the rubber layer, respectively. Based on the equations above, the shear modulus and MR effect of the samples are listed in Tables 3-4.

The dynamic shear tests showed that the MRE of 35\% iron volume fraction exhibited a maximum MR effect of $63.8 \%$ and $22.0 \%$ at strain amplitudes of $50 \%$ and $100 \%$, respectively. This is consistent with the observation by Lokander et al. 

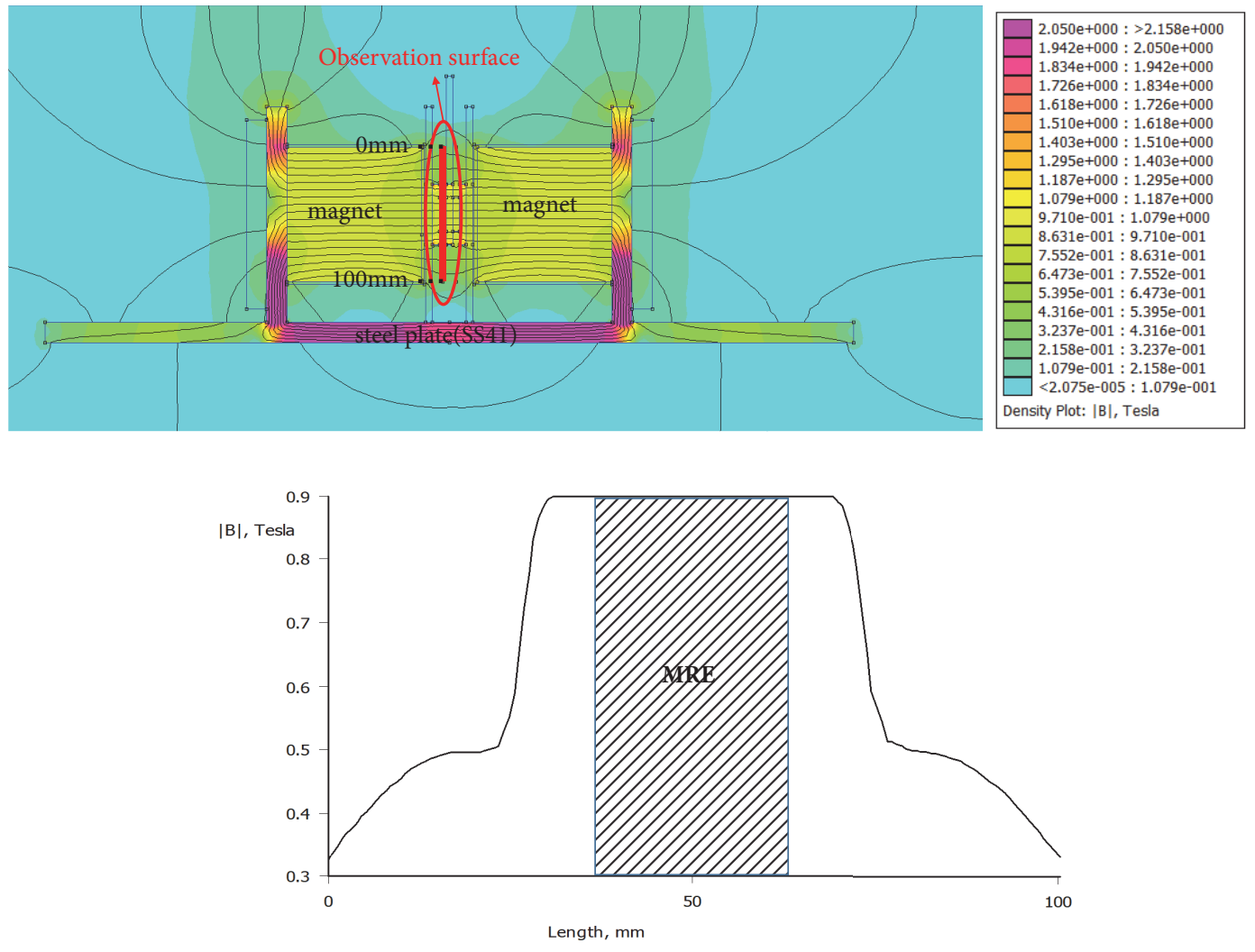

FIGURE 4: Numerical analysis of magnetic flux density results using Finite Element Magnetics (FEMM).

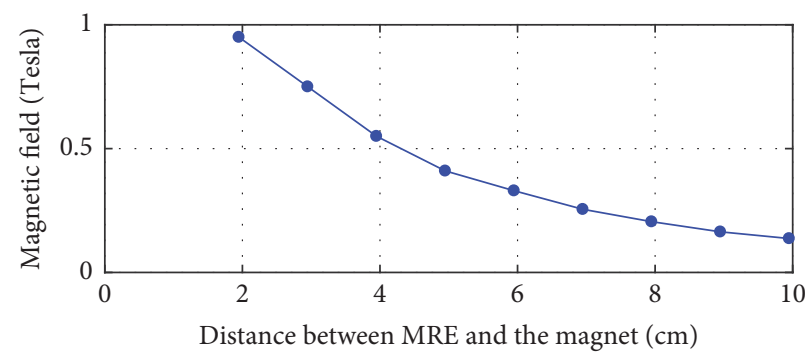

FIGURE 5: Magnetic field dependent on magnet distance from MRE.

[17] that the closer to CPVC (36.5\%) the higher the MR effect. Even with the MRE of the same iron ratio, the MRE at a low-strain amplitude showed a higher MR effect as shown in Figures 8-9. This indicates that the MR effect is high when the distances between the iron particles are close to each other due to the low strain. Chen et al. [16] reported that the anisotropic MRE applied with a magnetic field of $1 \mathrm{~T}$ during curing exhibited the $1200 \%$ higher MR effect than the isotropic MRE. However, the difference was not clear in this study. This is because this experiment was performed at a high-strain amplitude of more than $50 \%$ while the experiments of Chen et al. were tested at a low-strain amplitude of $0.3 \%$ (iron ratio: $11 \%$ ). As the strain amplitude increases, the direction of the applied magnetic field and the direction of the chain structure become more and more divergent. Therefore, in the case of $15 \%$ iron ratio (similar to $11 \%$ ), the difference of MR effect between isotropic and anisotropic MRE was less than $10 \%$. In the case of $25 \%$ iron ratio or more, the MR effect of the isotropic MRE was sometimes higher or similar to anisotropic MRE. The differences in absolute modulus change between isotropic and anisotropic samples were only $0.09 \mathrm{MPa}$ or less. That implies that the difference in arrangement of particles is meaningless due to the dense distribution. These results suggest that it is unnecessary to prepare the anisotropic MRE when using MRE containing high iron ratio (25\% or more) as a material for high-strain (about 100\%) base isolation devices. Unlike other devices, the base isolator is a very large device, so it is not easy to form chain structures by applying a magnetic field in advance. Therefore, unless there is a large difference, it seems that not forming the chain structure is advantageous in the manufacturing process. 


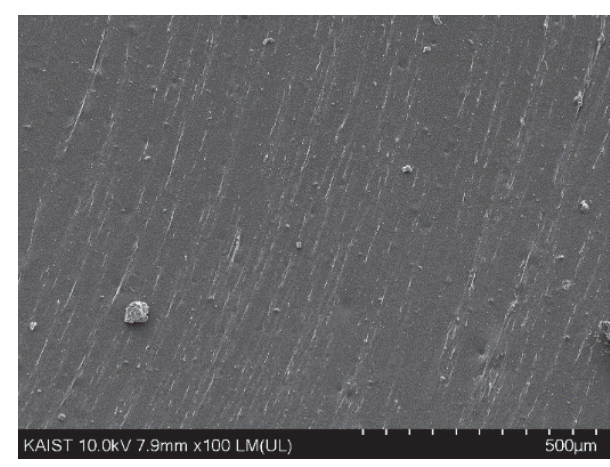

(a)

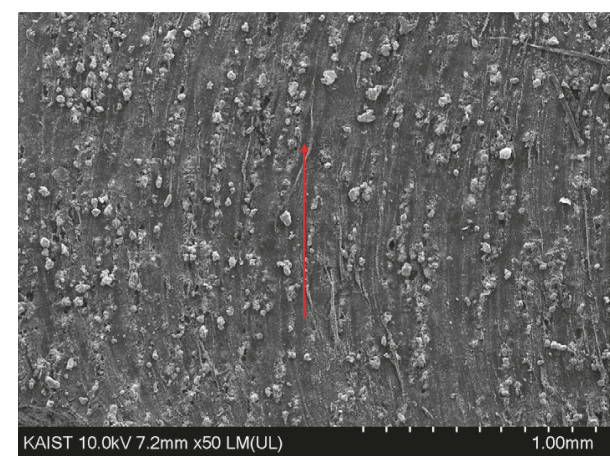

(c)

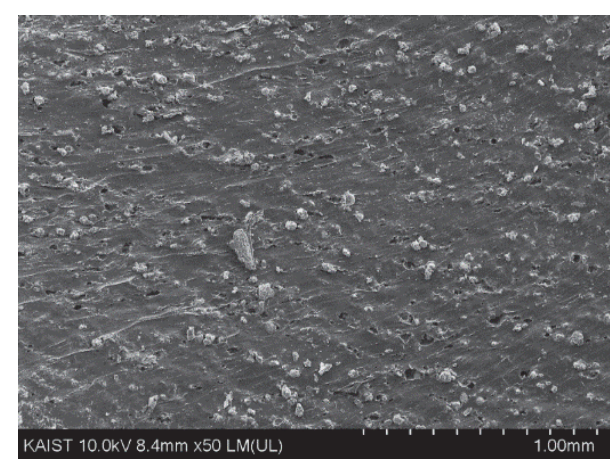

(b)

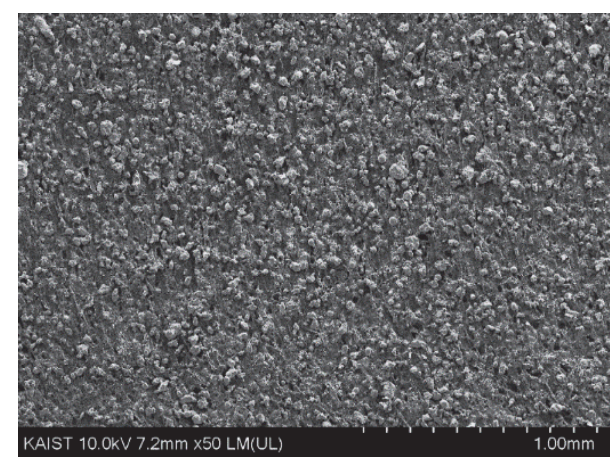

(d)

Figure 6: The microstructure of the samples observed by scanning electron microscope (SEM). (a) 0\%; (b) 15\% / Isotropic; (c) 15\% / Anisotropic; (d) 35\% / Anisotropic.

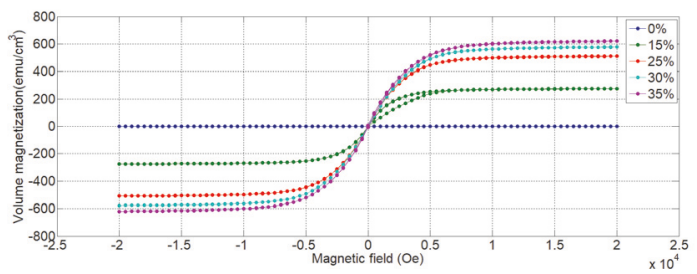

FIGURE 7: Magnetization curve of the MRE samples.

As shown in Figures 8-9, as the iron ratio increases, not only does the MR effect rise but also the area of the hysteresis loop increases. The area of the hysteresis loop means the amount of energy dissipation, and the damping ratio can be expressed as

$$
\xi=\frac{2 \Delta W}{\pi K_{h}\left(X_{1}-X_{2}\right)^{2}}
$$

where $\Delta W$ is the area of the hysteresis loop, $K_{h}$ is the stiffness, and $X_{1}, X_{2}$ represent the maximum and and minimum displacement, respectively. Using the above equation, the damping ratio trend of isotropic MREs (strain 50, 100\%, magnetic flux density 0, 0.94T) is plotted in Figure 10. The differences of damping ratio depending on the strain and the magnetic field were almost negligible or the correlation was unclear. However, as the iron volume fraction increased, the damping ratio obviously tended to increase from a minimum of $2.14 \%$ to a maximum of $10.29 \%$. This implies that the frictional force increases as the number of iron particles increases. According to Poojary et al. [33], the energy dissipation of the filler-matrix is expressed by the following:

$$
D_{p m}=n f s
$$

where $n$ is the number of interfaces, $f$ is the sliding friction force between the filler and the matrix, and $s$ is the relative displacement at the interface. The above equation can also explain the relationship between the number of iron particles and the amount of energy dissipation. Therefore, as a material of the base isolator, it is preferable to use a MRE with high iron ratio because it exhibits high attenuation performance.

3.2. Evaluation of MRE Properties with Carbon Black and Naphthenic Oil. In order to investigate the effect of carbon black and naphthenic oil on MRE, samples with five mixing 
TABLE 3: MR effect of MREs with various iron ratios ( $50 \%$ shear strain, $0.5 \mathrm{~Hz})$.

\begin{tabular}{|c|c|c|c|c|c|}
\hline Iron volume fraction (\%) & 0 & 15 & 25 & 30 & 35 \\
\hline Magnetic flux density $(\mathrm{T})$ & $0 / 0.94$ & $0 / 0.94$ & $0 / 0.94$ & $0 / 0.94$ & $0 / 0.94$ \\
\hline \multicolumn{6}{|l|}{ Isotropic } \\
\hline Shear modulus (MPa) & $0.35 / 0.35$ & $0.55 / 0.66$ & $0.71 / 0.95$ & $0.77 / 1.15$ & $0.85 / 1.31$ \\
\hline MR effect (\%) & 0 & 20.0 & 33.8 & 49.4 & 63.8 \\
\hline \multicolumn{6}{|l|}{ Anisotropic } \\
\hline Shear modulus (MPa) & - & $0.53 / 0.68$ & $0.73 / 0.93$ & $0.78 / 1.14$ & $0.82 / 1.24$ \\
\hline MR effect (\%) & - & 28.3 & 27.4 & 46.2 & 51.2 \\
\hline
\end{tabular}

TABLE 4: MR effect of MREs with various iron ratios (100\% shear strain, $0.5 \mathrm{~Hz})$.

\begin{tabular}{|c|c|c|c|c|c|}
\hline Iron volume fraction (\%) & 0 & 15 & 25 & 30 & 35 \\
\hline Magnetic flux density (T) & $0 / 0.94$ & $0 / 0.94$ & $0 / 0.94$ & $0 / 0.94$ & $0 / 0.94$ \\
\hline \multicolumn{6}{|l|}{ Isotropic } \\
\hline Shear modulus (MPa) & $0.32 / 0.32$ & $0.48 / 0.51$ & $0.58 / 0.65$ & $0.61 / 0.70$ & $0.62 / 0.74$ \\
\hline MR effect (\%) & 0 & 6.3 & 12.1 & 14.8 & 19.4 \\
\hline \multicolumn{6}{|l|}{ Anisotropic } \\
\hline Shear modulus (MPa) & - & $0.47 / 0.51$ & $0.58 / 0.66$ & $0.59 / 0.70$ & $0.59 / 0.72$ \\
\hline MR effect (\%) & - & 8.5 & 13.8 & 18.6 & 22.0 \\
\hline
\end{tabular}

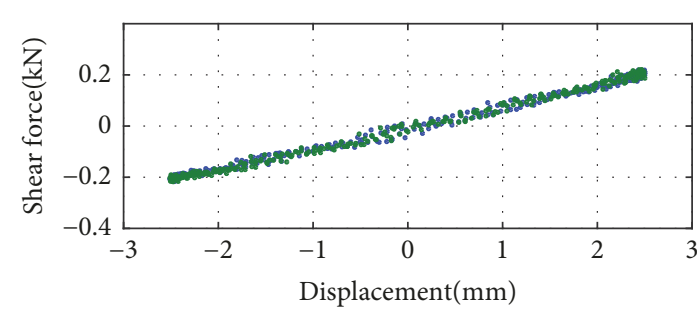

- 0Tesla

- 0.94Tesla

(a)

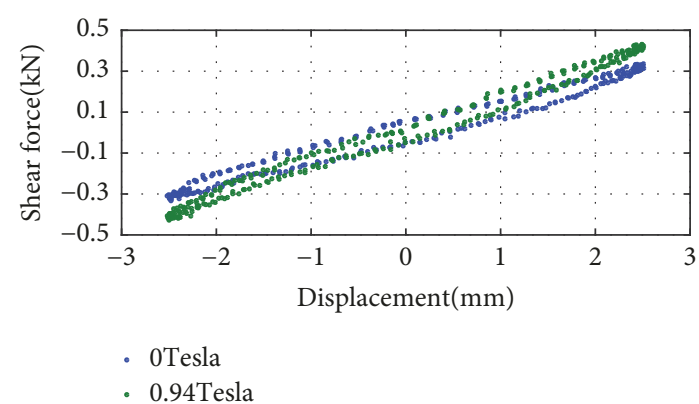

(c)

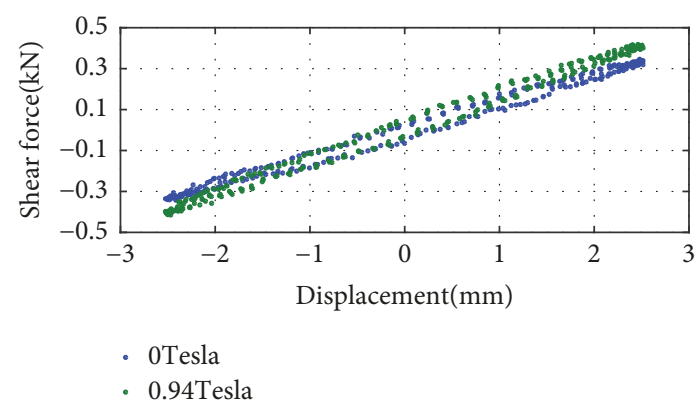

(b)

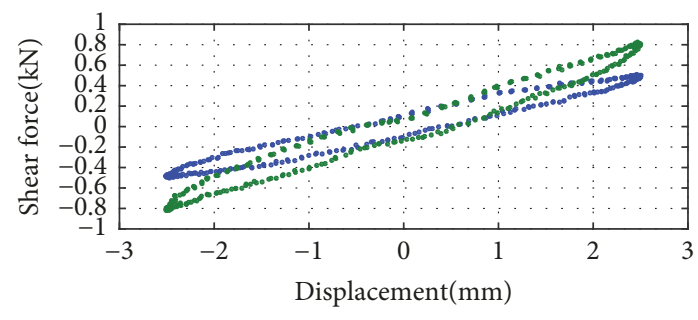

- 0Tesla

- 0.94Tesla

(d)

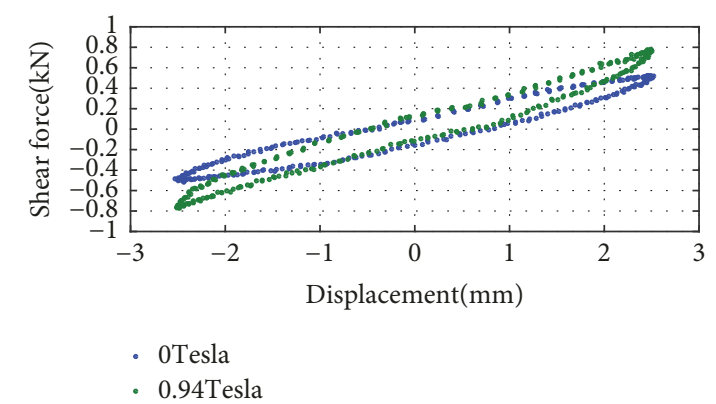

(e)

FIGURE 8: Force-displacement curves with varying magnetic field (0, $0.94 \mathrm{Tesla}, 50 \%$ shear strain, $0.5 \mathrm{~Hz}$ ). (a) $0 \%$; (b) $15 \%$ / isotropic; (c) $15 \%$ / anisotropic; (d) 35\% / isotropic; (e) 35\% / anisotropic. 

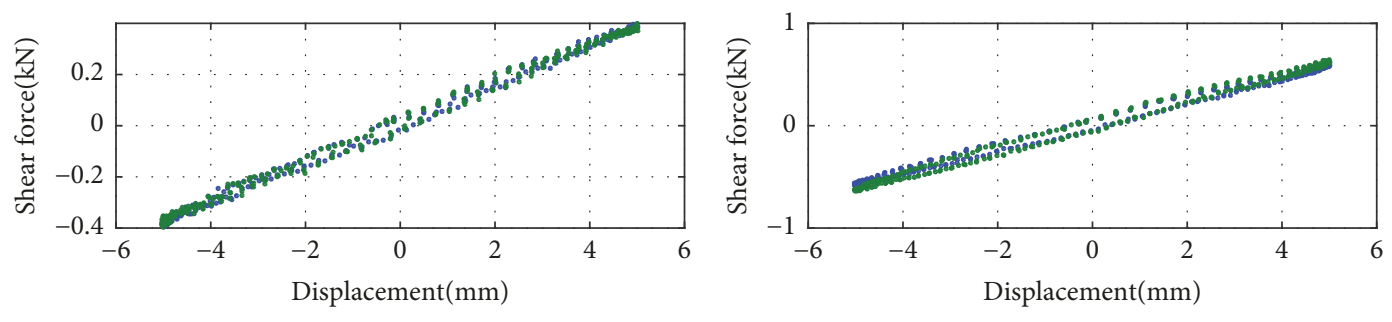

- 0Tesla

- 0.94Tesla

- 0Tesla

- 0.94Tesla

(a)
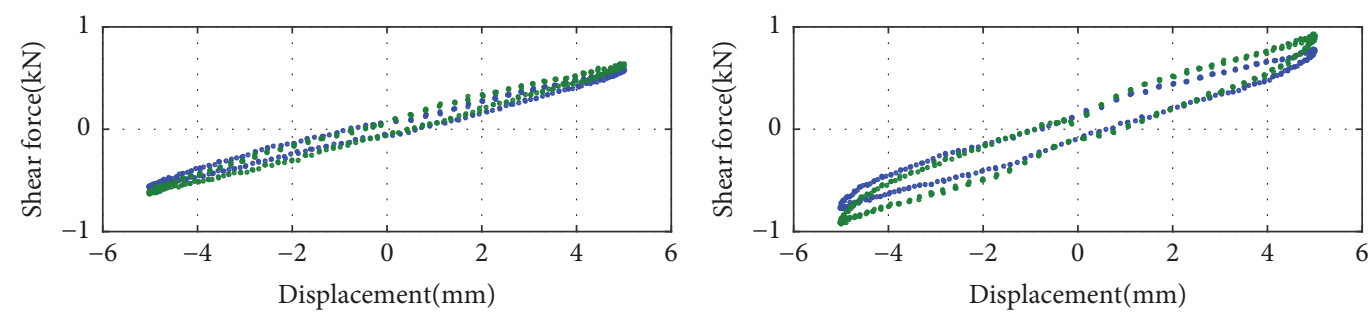

- 0Tesla

- 0Tesla

- 0.94Tesla

- 0.94Tesla

(c)

(d)

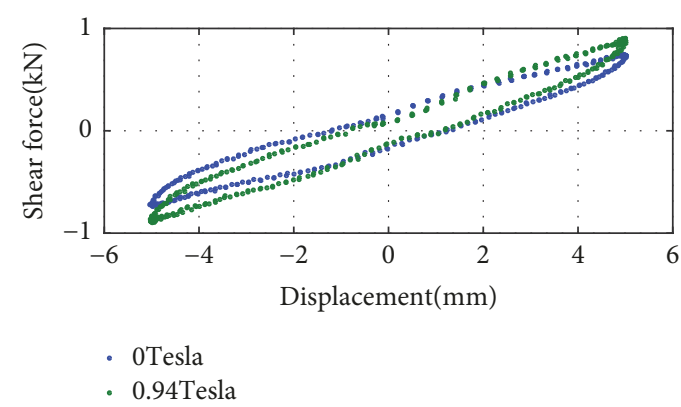

(e)

FIGURE 9: Force-strain curves with varying magnetic field (0, 0.94Tesla, $100 \%$ shear strain, $0.5 \mathrm{~Hz}$ ). (a) $0 \%$; (b) $15 \%$ / isotropic; (c) $15 \%$ / anisotropic; (d) 35\% / isotropic; (e) 35\% / anisotropic.

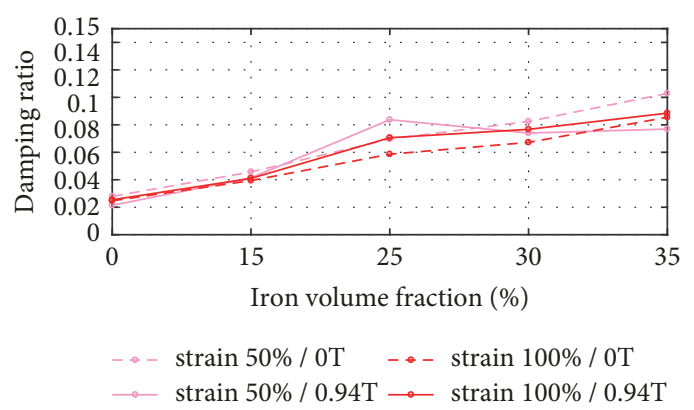

Figure 10: Damping ratio of isotropic MREs depending on iron volume fraction.

ratios were prepared as shown in Table 5. Since the rubber containing 70phr or more carbon black has been reported to be difficult to fabricate due to its high viscosity [34], the range up to $60 \mathrm{phr}$ was considered. In addition, the mechanical properties were controlled by the amount of oil. The volume fraction of iron powder was selected to be $35 \%$, which showed the highest MR effect in the previous experiment. To investigate the dependence of the MR effect on the external excitation conditions (strain amplitude, frequency), various experimental conditions are shown in Table 6.

The force-displacement curves of the above samples under 50\% strain are shown in Figure 11. In addition, The MR 
TABLE 5: MRE samples with various mixing ratio of carbon black and naphthenic oil (iron ratio: 35\%).

\begin{tabular}{lccccc}
\hline Sample & C20N20 & C40N20 & C20N40 & C40N40 & C60N40 \\
\hline Amount of carbon black (phr) & 20 & 40 & 20 & 40 & 60 \\
Amount of oil (phr) & 20 & 20 & 40 & 40 & 40 \\
\hline Mass ratio (\%) & & & & & \\
$\quad$ Rubber & 13.5 & 12.4 & 11.7 & 10.9 & 10.2 \\
Iron & 79.6 & 78.8 & 79.9 & 79.1 & 78.5 \\
Carbon black & 2.7 & 5.0 & 2.3 & 4.4 & 6.1 \\
Oil & 2.7 & 2.5 & 4.7 & 4.4 & 4.1 \\
etc. & 1.5 & 1.3 & 1.4 & 1.2 & 1.1 \\
\hline Volume ratio (\%) & & & & & 37.1 \\
Rubber & 48.3 & 44.9 & 42.0 & 39.4 & 35.0 \\
Iron & 35.0 & 35.0 & 35.0 & 35.0 & 11.3 \\
Carbon black & 4.9 & 9.1 & 4.2 & 8.0 & 14.9 \\
Oil & 9.7 & 9.0 & 16.8 & 15.8 & 1.8 \\
etc. & 2.1 & 2.0 & 2.0 & & 1.8 \\
\hline
\end{tabular}

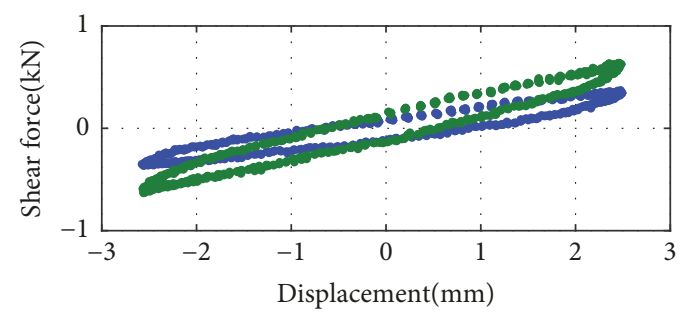

- 0Tesla

- 0.94Tesla

(a)

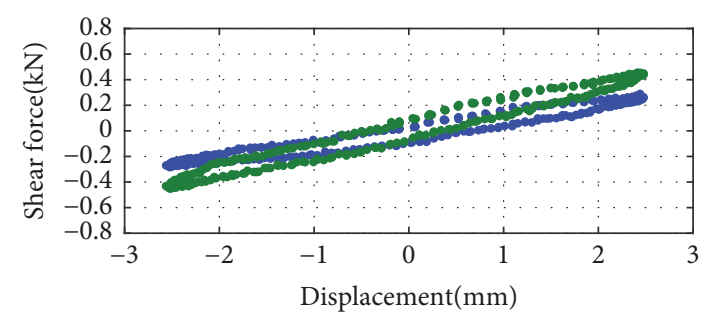

- 0Tesla

- 0.94Tesla

(c)

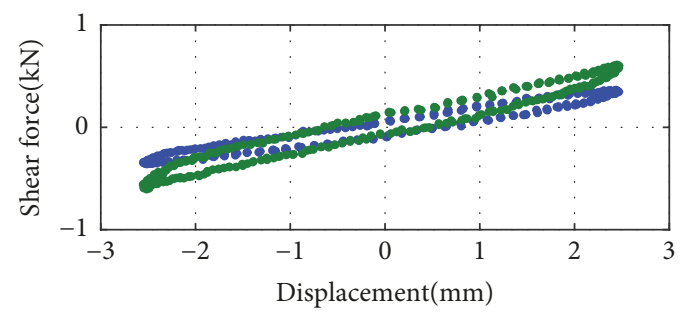

- 0Tesla

- 0.94Tesla

(b)

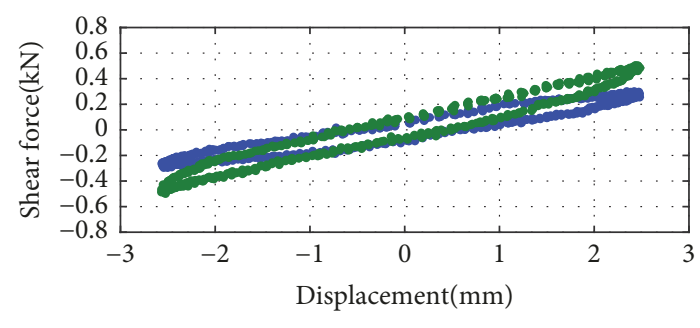

- 0Tesla

- 0.94Tesla

(d)

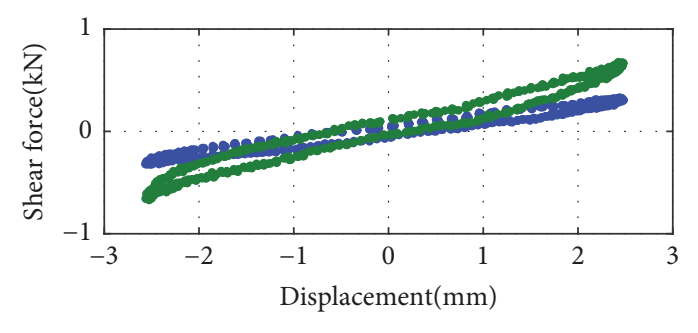

- 0Tesla

- 0.94Tesla

(e)

Figure 11: Force-displacement curves with varying magnetic field (0, 0.94Tesla, 50\% shear strain, 0.5Hz). (a) C20N20; (b) C40N20; (c) C20N40; (d) C40N40; (e) C60N40. 
TABLE 6: Dynamic shear test conditions.

\begin{tabular}{lcccc}
\hline Test & Shear strain $(\%)$ & Frequency $(\mathrm{Hz})$ & Number of cycles & Temperature \\
\hline Strain dependency & $25,50,75,100$ & 0.5 & 11 & Room temperature $\left(23 \sim 25^{\circ} \mathrm{C}\right)$ \\
Frequency dependency & 100 & $0.5,1,2$ & & \\
\hline
\end{tabular}

TABLE 7: MR effect of MRE with carbon black and naphthenic oil (0.5hz).

\begin{tabular}{|c|c|c|c|c|c|c|}
\hline \multicolumn{2}{|l|}{ Sample } & C20N20 & C40N20 & C20N40 & C40N40 & C60N40 \\
\hline \multicolumn{2}{|c|}{ Magnetic flux density $(\mathrm{T})$} & $0 / 0.94$ & $0 / 0.94$ & $0 / 0.94$ & $0 / 0.94$ & $0 / 0.94$ \\
\hline \multirow{12}{*}{ Strain $(\%)$} & 25 & & & & & \\
\hline & Shear modulus (MPa) & $0.80 / 1.45$ & $0.76 / 1.32$ & $0.66 / 1.08$ & $0.69 / 1.13$ & $0.67 / 1.53$ \\
\hline & MR effect (\%) & 80.2 & 72.5 & 64.0 & 64.3 & 127.4 \\
\hline & \multicolumn{6}{|l|}{50} \\
\hline & Shear modulus (MPa) & $0.58 / 1.00$ & $0.58 / 0.97$ & $0.45 / 0.72$ & $0.47 / 0.79$ & $0.52 / 1.07$ \\
\hline & MR effect (\%) & 73.1 & 67.9 & 58.2 & 67.9 & 106.9 \\
\hline & \multicolumn{6}{|l|}{75} \\
\hline & Shear modulus (MPa) & $0.49 / 0.75$ & $0.50 / 0.76$ & $0.39 / 0.57$ & $0.39 / 0.60$ & $0.45 / 0.78$ \\
\hline & MR effect (\%) & 53.3 & 52.2 & 47.5 & 54.2 & 71.2 \\
\hline & \multicolumn{6}{|l|}{100} \\
\hline & Shear modulus (MPa) & $0.42 / 0.56$ & $0.47 / 0.60$ & $0.35 / 0.44$ & $0.38 / 0.48$ & $0.45 / 0.60$ \\
\hline & MR effect (\%) & 33.2 & 26.9 & 27.1 & 26.6 & 33.5 \\
\hline
\end{tabular}

effects of the whole experiment are summarized in Table 7. Experimental results show that the C60N40 sample showed the highest MR effect of $127.4 \%$ at $25 \%$ strain and $33.5 \%$ at $100 \%$ strain, respectively. This shows that the addition of carbon black and oil to the MRE increases the MR effect. Compared to the case without additives, it showed obvious improvement by $43.1 \%$ and $14.1 \%$ at $50 \%$ and $100 \%$ strain, respectively. Chen et al. [15] observed the improvement of the MR effect by adding carbon black up to a volume ratio of $7 \%$ forming a good bond. On the other hand, the research also reported that excessive addition of carbon black rapidly increased the zero-field modulus, thereby reducing the relative MR effect. In this experiment, the MREs were synthesized by adjusting the amount of carbon black and the amount of oil. As a result, the MRE containing $60 \mathrm{phr}$ of carbon black and 40 phr of oil was successfully synthesized, while the MRE containing $60 \mathrm{phr}$ of carbon black and $20 \mathrm{phr}$ of oil was too stiff to be synthesized. The zero-field modulus of the MRE containing $60 \mathrm{phr}$ of carbon black and $40 \mathrm{phr}$ of oil was even decreased compared to the case without additives. Therefore, even at a high ratio of $11.3 \%$ carbon black, a high MR effect could be achieved. Nevertheless, the shear modulus was maintained above $0.45 \mathrm{MPa}$. In other words, the addition of oil increased the carbon black ratio still retained sufficient strength. As with the first step, the MR effect tended to decrease as the strain increased. This means that the smaller the strain range of the MRE isolator, the larger the control range. Therefore, it seems to be advantageous to design the height of the MRE isolator as high as possible. In the frequency dependency test, there was no significant difference in the force-displacement curve according to the frequency change under the large strain. Figure 12 shows that there is little difference in the hysteresis curves for the frequencies of the C20N20 sample with the least amount of additives and the C60N40 sample with the largest amount of additives.

\section{Conclusion}

Various MRE samples were prepared to investigate the material properties under large-strain range for application of base isolators. In the first step, MRE samples with various iron volume fractions were produced in two types of isotropic and anisotropic types. As a result of the microstructure observation, the anisotropic MRE with the $15 \%$ iron ratio formed chain structures according to the direction of the magnetic field, but the MRE with the high iron ratio of $35 \%$ had a dense distribution and the chain structures were hard to be observed. In the magnetization curves, it was found that the higher the iron ratio is, the higher the magnetic saturation was achieved and the higher the influence by the magnetic field is. The dynamic shear tests results showed that the isotropic MRE with an iron volume fraction of 35\% accomplished highest MR effect of $63.8 \%$ under $50 \%$ strain. The magnitude of energy dissipation tended to increase with the amount of iron and the highest damping ratio was $10.29 \%$ in the MRE with 35\% iron ratio (isotropic, 50\% strain). In addition, under the condition of high strain (100\%) and high iron ratio (25\% or more), MR effects of isotropic and anisotropic MRE did not show any significant difference. This suggests that it is unnecessary to prepare the anisotropic MRE when using MRE containing high iron ratio as a material for high-strain base isolators. In the second step, MREs were prepared with the addition of carbon black and naphthenic oil at various mixing ratios to the iron ratio of $35 \%$, which showed the highest MR effect in the first step. Among them, the MRE containing $60 \mathrm{phr}$ of carbon black and $40 \mathrm{phr}$ of oil was successfully synthesized, while the MRE containing 


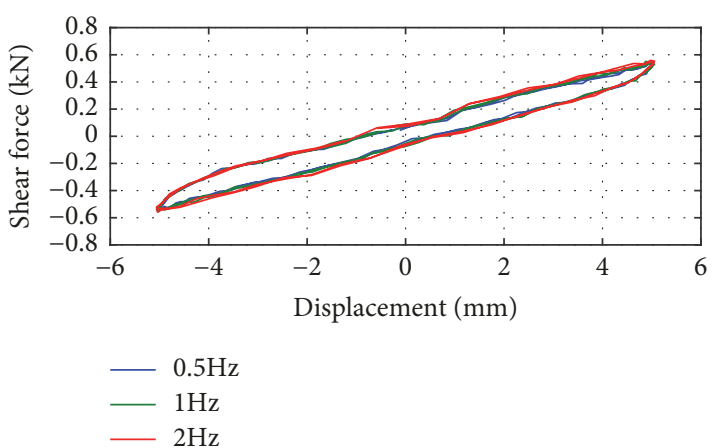

(a)

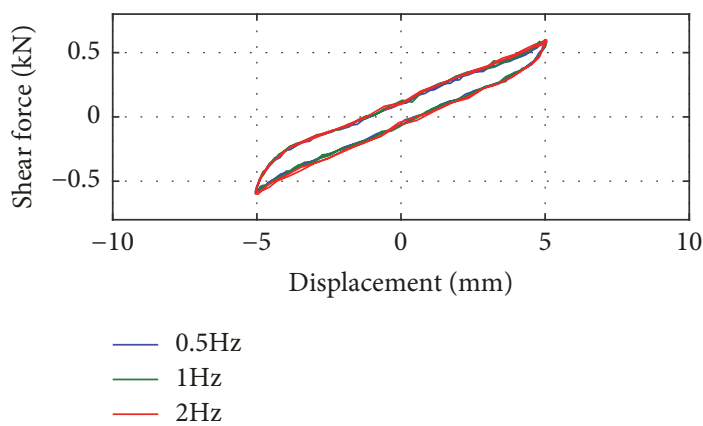

(c)

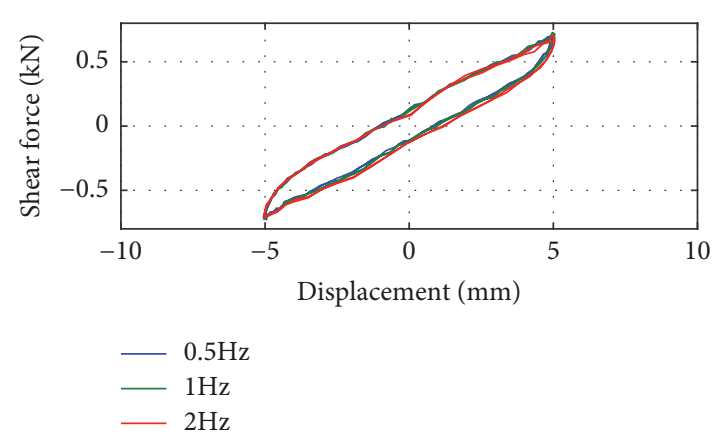

(b)

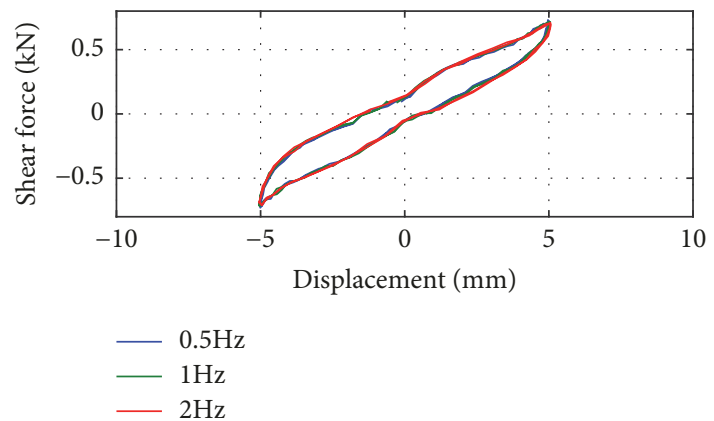

(d)

FIGURE 12: Force-displacement curves with varying external frequency (100\% strain, 0.5 2Hz). (a) C20N20 (0Tesla); (b) C20N20 (0.94Tesla); (c) C60N40 (0Tesla); (d) C60N40 (0.94Tesla).

$60 \mathrm{phr}$ of carbon black and $20 \mathrm{phr}$ of oil was too stiff to be synthesized. This shows that increasing the amount of oil can increase the content of carbon black. As a result, the MRE containing $60 \mathrm{phr}$ of carbon black and $40 \mathrm{phr}$ of naphthenic oil had the highest MR effect of $127.4 \%$ at $25 \%$ strain and $33.5 \%$ at $100 \%$ strain, respectively. Compared to the case without additives, it showed obvious improvement by $43.1 \%$ and $14.1 \%$ at $50 \%$ and $100 \%$ strain, respectively. Under various strains (25\% 100\%), the MR effect tended to decrease as the strain increased. In other words, the larger the strain range of the MRE isolator, the narrower the control range. In the frequency dependence $(0.5 \sim 2 \mathrm{~Hz})$ test, the hysteresis curves of the frequencies were almost the same. These results will be helpful to develop base isolation system based on MRE.

\section{Conflicts of Interest}

The authors declare that there are no conflicts of interest.

\section{Acknowledgments}

This research was supported by a grant from Technology Advancement Research Program (TARP) Program funded by Ministry of Land, Infrastructure and Transport of Korean Government (17CTAP-C129736-01).

\section{References}

[1] Scawthorn, Charles, and Wai-Fah Chen, Eds., Earthquake engineering handbook, CRC press, 2002.
[2] T. A. Morgan and S. A. Mahin, "Performance-based design of seismic isolated buildings considering multiple performance objectives," Smart Structures and Systems, vol. 4, no. 5, pp. 655666, 2008.

[3] R. S. Jangid and J. M. Kelly, "Base isolation for near-fault motions," Earthquake Engineering \& Structural Dynamics, vol. 30, no. 5, pp. 691-707, 2001.

[4] S. Nagarajaiah, "Structural control benchmark problem: Smart base isolated building subjected to near fault earthquakes," Structural Control and Health Monitoring, vol. 13, no. 2-3, pp. 571-572, 2006.

[5] K. Chopra Anil and Chatpan. Chintanapakdee, "Comparing response of SDF systems to near-fault and far-fault earthquake motions in the context of spectral regions," Earthquake Engineering \& Structural Dynamics, pp. 1769-1789, 2001.

[6] M. R. Jolly, J. D. Carlson, and B. C. Muñoz, "A model of the behaviour of magnetorheological materials," Smart Materials and Structures, vol. 5, no. 5, pp. 607-614, 1996.

[7] L. C. Davis, "Model of magnetorheological elastomers," Journal of Applied Physics, vol. 85, no. 6, pp. 3348-3351, 1999.

[8] M. Lokander and B. Stenberg, "Performance of isotropic magnetorheological rubber materials," Polymer Testing, vol. 22, no. 3, pp. 245-251, 2003.

[9] "Ruddy, C., E. Ahearne, and G. Byrne, "A review of magnetorheological elastomers: properties and applications," Advanced Manufacturing Science (AMS) Research. http://www. ucd. ie/mecheng/ams/news_items/Cillian\% 20Ruddy. pdf Accessed20, 2012".

[10] Clutch, F. Magnetic, and J. Rabinow, "Technical News Bulletin,” National Bureau of Standards, vol. 32, no. 4, pp. 54-60, 1948. 
[11] J. Rabinow, "Magnetic fluid torque and force transmitting device," US Patent Specification, Article ID 2575360, 1951.

[12] Y. Li, J. Li, W. Li, and H. Du, "A state-of-the-art review on magnetorheological elastomer devices," Smart Materials and Structures, vol. 23, no. 12, Article ID 123001, 2014.

[13] G. Y. Zhou, "Shear properties of a magnetorheological elastomer," Smart Materials and Structures, vol. 12, no. 1, pp. 139146, 2003.

[14] M. Kallio, "The elastic and damping properties of magnetorheological elastomers," VTT Publications, no. 565, pp. 3-146, 2005.

[15] L. Chen, X. L. Gong, and W. H. Li, "Effect of carbon black on the mechanical performances of magnetorheological elastomers," Polymer Testing, vol. 27, no. 3, pp. 340-345, 2008.

[16] L. Chen, X. L. Gong, and W. H. Li, "Microstructures and viscoelastic properties of anisotropic magnetorheological elastomers," Smart Materials and Structures, vol. 16, no. 6, pp. 26452650, 2007.

[17] M. Lokander and B. Stenberg, "Improving the magnetorheological effect in isotropic magnetorheological rubber materials," Polymer Testing, vol. 22, no. 6, pp. 677-680, 2003.

[18] M. Behrooz, X. Wang, and F. Gordaninejad, "Performance of a new magnetorheological elastomer isolation system," Smart Materials and Structures, vol. 23, no. 4, Article ID 045014, 2014.

[19] Y. Li, J. Li, T. Tian, and W. Li, "Erratum: A highly adjustable magnetorheological elastomer base isolator for applications of real-time adaptive control (Smart Materials and Structures (2013) 22 (095020))," Smart Materials and Structures, vol. 23, no. $12,2014$.

[20] Y. Li, J. Li, W. Li, and B. Samali, "Development and characterization of a magnetorheological elastomer based adaptive seismic isolator," Smart Materials and Structures, vol. 22, no. 3, Article ID 035005, 2013.

[21] Y. Li, J. Li, and W. Li, "Design and experimental testing of an adaptive magneto-rheological elastomer base isolator," in Proceedings of the 2013 IEEE/ASME International Conference on Advanced Intelligent Mechatronics: Mechatronics for Human Wellbeing, AIM 2013, pp. 381-386, aus, July 2013.

[22] Y. Li and J. Li, "Finite element design and analysis of adaptive base isolator utilizing laminated multiple magnetorheological elastomer layers," Journal of Intelligent Material Systems and Structures, vol. 26, no. 14, pp. 1861-1870, 2015.

[23] W. Li, X. Qiao, X. Lu et al., "Microstructure and magnetorheological properties of the thermoplastic magnetorheological elastomer composites containing modified carbonyl iron particles and poly(styrene-b-ethylene-ethylenepropylene-b-styrene) matrix," Smart Materials and Structures, vol. 21, no. 11, 2012.

[24] X.-M. Dong, M. Yu, C.-R. Liao, and W.-M. Chen, "A new variable stiffness absorber based on magneto-rheological elastomer," Transactions of Nonferrous Metals Society of China, vol. 19, no. 3, pp. s611-s615, 2009.

[25] C. Y. Yang, J. Fu, M. Yu, X. Zheng, and B. X. Ju, "A new magnetorheological elastomer isolator in shear-compression mixed mode," Journal of Intelligent Material Systems and Structures, vol. 26, no. 10, pp. 1290-1300, 2015.

[26] S. Opie and W. Yim, "Design and control of a real-time variable modulus vibration isolator," Journal of Intelligent Material Systems and Structures, vol. 22, no. 2, pp. 113-125, 2011.

[27] Z.-W. Xing, M. Yu, J. Fu, Y. Wang, and L.-J. Zhao, "A laminated magnetorheological elastomer bearing prototype for seismic mitigation of bridge superstructures," Journal of Intelligent Material Systems and Structures, vol. 26, no. 14, pp. 1818-1825, 2015.
[28] N. A. Wahab, S. A. Mazlan, . Ubaidillah et al., "Fabrication and investigation on field-dependent properties of natural rubber based magneto-rheological elastomer isolator," Smart Materials and Structures, vol. 25, no. 10, p. 107002, 2016.

[29] L. Chen, X.-L. Gong, W.-Q. Jiang, J.-J. Yao, H.-X. Deng, and W.$\mathrm{H}$. Li, "Investigation on magnetorheological elastomers based on natural rubber," Journal of Materials Science, vol. 42, no. 14, pp. 5483-5489, 2007.

[30] ISO 22762-1 (2010) Elastomeric seismic protection isolators.

[31] Meeker, David. "Finite element method magnetics." FEMM4 (2010): 32 .

[32] L. Mullins and N. R. Tobin, "Stress softening in rubber vulcanizates. Part I. Use of a strain amplification factor to describe the elastic behavior of filler-reinforced vulcanized rubber," Journal of Applied Polymer Science, vol. 9, no. 9, pp. 2993-3009, 1965.

[33] U. R. Poojary and K. V. Gangadharan, "Magnetic field and frequency dependent LVE limit characterization of magnetorheological elastomer," Journal of the Brazilian Society of Mechanical Sciences and Engineering, vol. 39, no. 4, pp. 13651373, 2017.

[34] J. Wootthikanokkhan and N. Rattanathamwat, "Distribution of carbon black in natural rubber/acrylic rubber blends," Journal of Applied Polymer Science, vol. 102, no. 1, pp. 248-256, 2006. 


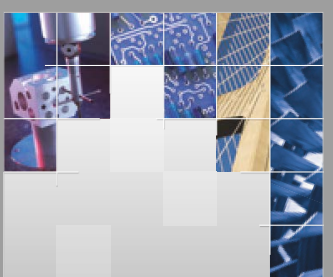

\section{Enfincering}
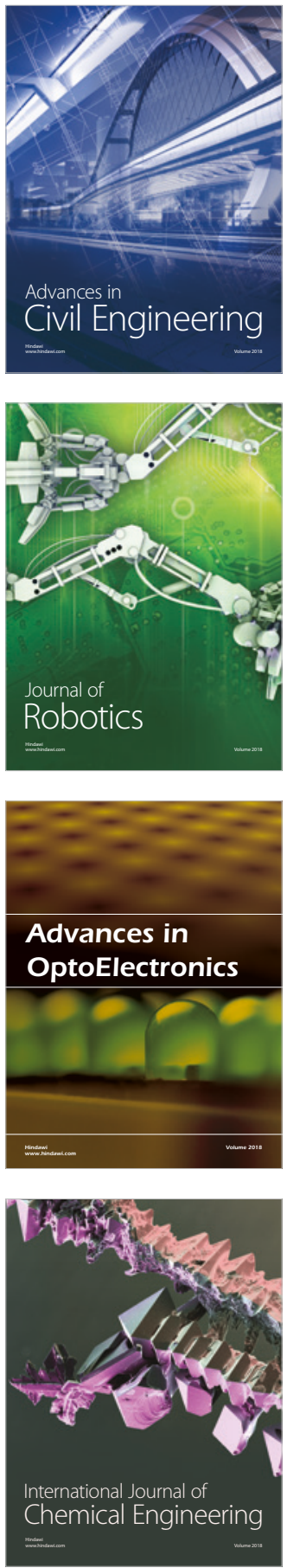

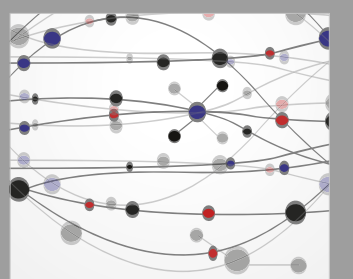

\section{Rotating \\ Machinery}

The Scientific World Journal

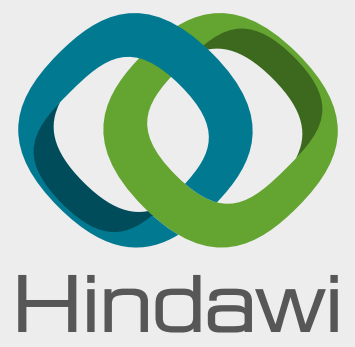

Submit your manuscripts at

www.hindawi.com
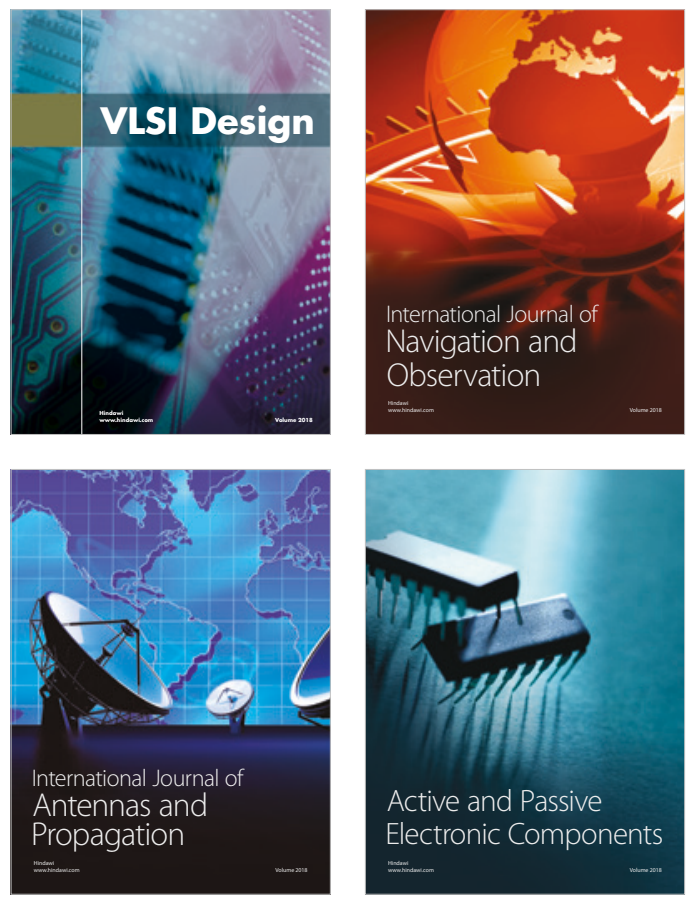
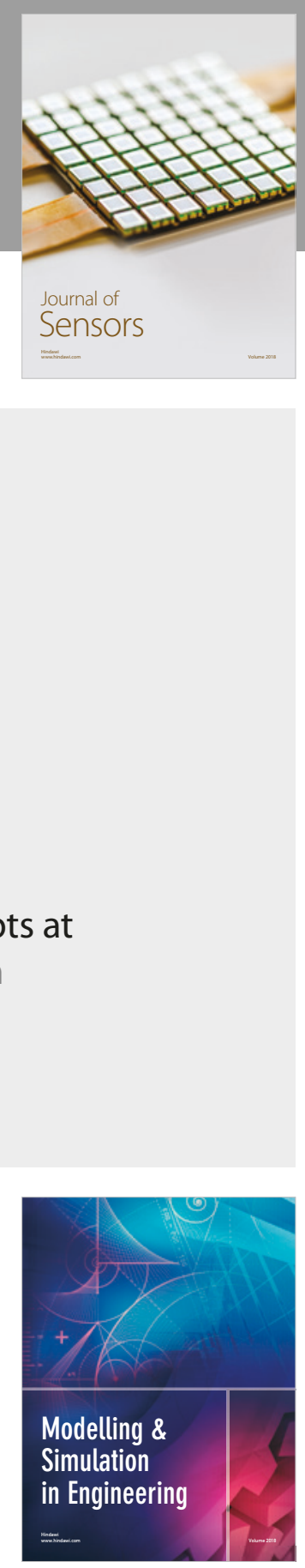

\section{Advances \\ Multimedia}
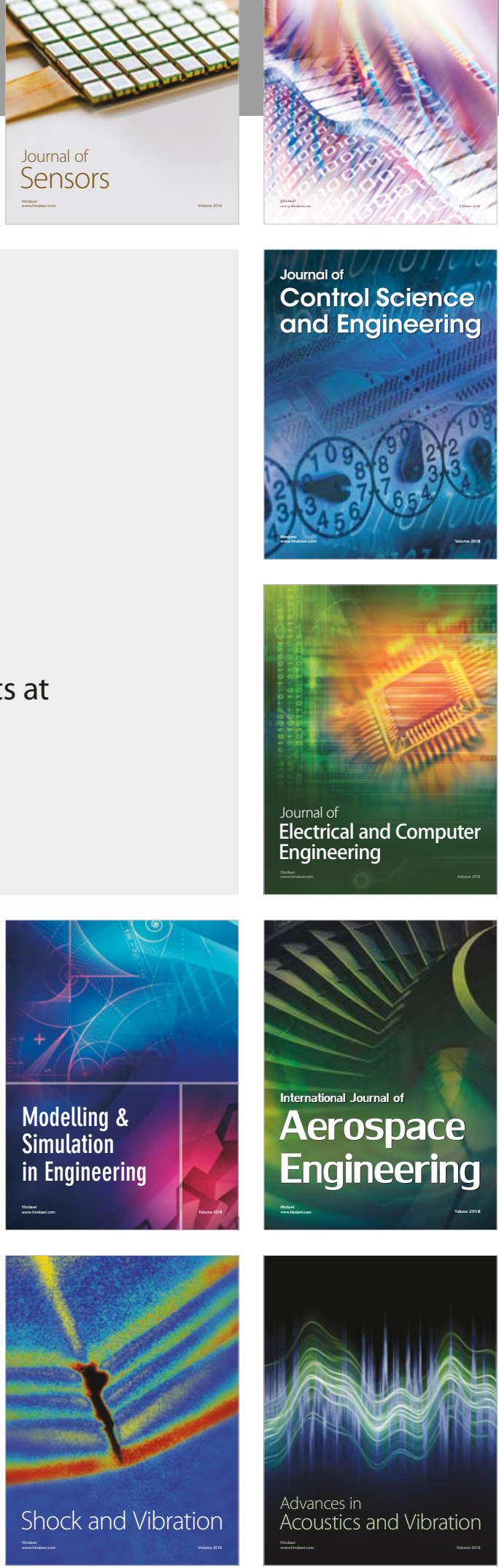